\title{
Efektivitas pembelajaran matematika berbasis E-Learning pada materi sistem persamaan linear dua variabel kelas VIII di MTSN 1 Mataram
}

\author{
Ulia Safitri ${ }^{*}$, Baidowi ${ }^{2}$, Wahidaturrahmi ${ }^{2}$, Nani Kurniati ${ }^{2}$ \\ ${ }_{1}^{1}$ Mahasiswa Pendidikan Matematika, FKIP, Universitas Mataram, Mataram \\ 2 Pendidikan Matematika, FKIP, Universitas Mataram, Mataram \\ uliasafitri24@gmail.com \\ Diterima:17-12-2021; Direvisi: 29-12-2021; Dipublikasi: 30-12-2021
}

\begin{abstract}
The purpose of this study was to determine the effectiveness of e-learning based mathematics learning on the material of the two-variable linear equation system for class VIII at MTsN 1 Mataram. This type of research is a descriptive study using a quantitative approach. The research design used a post-test-only control design. All students of class VIII at MTsN 1 Mataram were the population and the sampling technique used cluster random sampling. The sample used was class VIII-8 and VIII-9 who were a member of one sample group. The data in the study were analyzed using descriptive statistics and paired sample t-test to determine whether or not e-learning based mathematic learning was effective in the material of the two-variable linear equation system. Based on the results of data analysis, it is known that e-learning-based mathematics learning with learning video is effectively applied to the material of the two-variable linear equation system for class VIII students at MTsN 1 Mataram the academic year 2020/2021.
\end{abstract}

Keywords: e-learning mathematics; system of linear equations of two variables

\begin{abstract}
Abstrak
Tujuan dari penelitian ini adalah untuk mengetahui efektivitas pembelajaran matematika berbasis elearning pada materi sistem persamaan linear dua variabel kelas VIII di MTsN 1 Mataram. Jenis penelitian yakni penelitian deskriptif dengan menggunakan pendekatan kuantitatif. Desain penelitian menggunakan post-test only control design. Seluruh siswa kelas VIII di MTsN 1 Mataram merupakan populasi dan teknik pengambilan sampel menggunakan cluster random sampling. Sampel yang digunakan yaitu kelas VIII-8 dan VIII-9 yang tergabung dalam satu kelompok sampel. Data dalam penelitian dianalisis menggunakan statistik deskriptif dan uji-t paired sample untuk mengetahui efektif atau tidak pembelajaran matematika berbasis e-learning pada materi sistem persamaan linear dua variabel. Berdasarkan hasil analisis data diperoleh bahwa pembelajaran matematika berbasis e-learning dengan media video pembelajaran efektif diterapkan pada materi sistem persamaan linear dua variabel kelas VIII di MTsN 1 Mataram tahun ajaran 2020/2021.
\end{abstract}

Kata Kunci: e-learning matematika; sistem persamaan linear dua variabel

\section{PENDAHULUAN}

Pendidikan dan teknologi memiliki pengaruh penting dan dapat saling melengkapi, dimana pendidikan yang meliputi pembelajaran matematika dapat didukung dengan sesuatu yang baru misalnya dengan memanfaatkan perkembangan teknologi. Sesuai pendapat Sutarto \& Wuryanto (2018), pendidikan matematika yang diajarkan pada jalur sekolah sangat diperlukan guna menguasai ilmu pengetahuan dan teknologi. Selain itu, Nu'man (2014) menyatakan bahwa perkembangan teknologi informasi sangat cepat serta 
memberikan kemudahan bagi seseorang untuk mendapatkan informasi, pemenuhan informasi sangat mudah dengan hadirnya internet, pada bidang pendidikan teknologi internet merupakan sarana pembelajaran yang disebut e-learning.

Adanya pandemi covid-19 melanda seluruh negeri di belahan dunia termasuk Indonesia. Pemerintah melalui kementerian pendidikan dan kebudayaan (Kemendikbud) melakukan penyesuaian proses pembelajaran dengan memindahkan proses belajar mengajar di Sekolah menjadi di Rumah dengan menerapkan pembelajaran online (elearning). Menurut Fathurrohman \& Sulistyorini (2012:284), pada era modern ini, proses pembelajaran tidak hanya dapat dilakukan dengan tatap muka namun, juga bisa dilakukan dengan jarak jauh atau e-learning. Sesuai dengan pendapat Fathurrohman \& Sulistyorini tersebut guru dapat menggunakan model e-learning agar proses belajar mengajar tetap terlaksana. Namun, pelaksanaan proses pembelajaran secara online memiliki beberapa kendala.

Berdasarkan informasi dari salah seorang guru matematika kelas VIII di MTs Negeri 1 Mataram saat melakukan observasi melalui WhatsApp 11 juli 2020, kendala dalam $e$ learning yaitu sebagian peserta didik tidak mempunyai kuota, guru kesulitan mengontrol kelas karena tidak dapat mengawasi peserta didik sepenuhnya, dan jika diberikan latihan soal ada sebagian peserta didik yang responnya lama bahkan sampai satu minggu tidak merespon.

Dalam proses pembelajaran guru menggunakan website e-learning MTs Negeri 1 Mataram yang dapat diakses melalui link https://elearning.mtsnmataram1.sch.id. Sedangkan pemberian materi dan latihan soal dilakukan dengan cara mengirimkan file materi berbentuk file Microsoft word. Dalam website e-learning MTsN 1 Mataram terdapat beberapa fitur-fitur yang dapat membantu guru dalam proses pembelajaran seperti fitur video conference. Akan tetapi, guru belum pernah memanfaatkan fitur tersebut. Guru juga belum pernah menerapkan pembelajaran menggunakan media video pembelajaran selama proses pembelajaran e-learning. Menurut informasi dari salah seorang siswa, mereka merasa bosan dan kurang berminat dalam pembelajaran matematika karena dalam proses pembelajaran matematika hanya diberikan materi dan latihan soal dalam bentuk file Microsoft word. Untuk standar KKM (Kriteria Ketuntasan Minimal) individu pada mata pelajaran matematika di MTs Negeri 1 Mataram yaitu 80. Sedangkan standar ketuntasan klasikalnya 78\%. Dilihat dari hasil perolehan nilai ulangan harian pembelajaran matematika pada materi aritmatika di kelas VII-8 ketuntasan klasikalnya yaitu 43,75\%.

Menurut Hamdani (2011:60) tingkat penguasaan materi dalam konsep ketuntasan belajar ditetapkan antara 75\% - 85\%. Berdasarkan konsep tuntas, maka pembelajaran yang efektif adalah setiap peserta didik dapat menguasai $75 \%$ dari materi yang diajarkan. Oleh karena itu, pembelajaran yang dilakukan oleh guru masih belum dapat dikategorikan efektif.

Diperlukan inovasi dalam pembelajaran matematika di kelas agar siswa tidak merasa bosan untuk belajar matematika walaupun dalam keadaan mewabahnya covid-19 yang menyebabkan siswa harus belajar tidak melalui tatap muka melainkan menggunakan 
pembelajaran berbasis e-learning. Inovasi tersebut dapat berupa penerapan pembelajaran matematika berbasis e-learning dengan menggunakan website e-learning MTsN 1 Mataram dengan berbantuan media video pembelajaran yang dibuat menggunakan aplikasi screen recorder, dalam media video pembelajaran akan ditampilkan pembahasan mengenai materi dan pembahasan contoh soal sistem persamaan linear dua variabel dengan menggunakan aplikasi power point. Sehingga materi pembelajaran matematika yang akan disampaikan menjadi lebih menarik. Oleh karena itu, diharapkan dapat meningkatkan minat belajar siswa dalam memahami konsep matematika secara mandiri. Sesuai pendapat Ristianti (2017) pembelajaran menggunakan media video dapat meningkatkan minat belajar siswa. Sehingga dengan meningkatnya minat belajar siswa maka diharapkan hasil belajar siswa juga meningkat.

Menurut Zulkardi (2002), penggunaan website sebagai lingkungan belajar bagi siswa sangat membantu proses peningkatan pemahaman matematika siswa karena sangat mudah ditelusuri tanpa adanya pembatasan ruang dan waktu ketika diperlukan. Selain media website, media e-learning yang digunakan dalam penelitian ini adalah WhatsApp Group. WhatsApp Group digunakan untuk mengontol kelas dan mengirim video pembelajaran yang dibuat oleh guru dengan menggunakan aplikasi screen recorder, dimana dalam video pembelajaran tersebut berisi penjelasan materi dan pembahasan contoh soal sistem persamaan linear dua variabel.

Materi sistem persamaan linear dua variabel merupakan salah satu bab dalam pelajaran matematika kelas VIII. Pemilihan materi sistem persmaan linear dua variabel karena menyesuaikan dengan media yang akan digunakan yaitu aplikasi power point. Peneliti memilih kelas VIII sebagai objek penelitian karena kelas VII baru saja menempuh sekolah menengah dan langsung diterapkan pembelajaran online sedangkan mereka masih membutuhkan penyesuaian diri. Dan untuk kelas IX mereka sudah fokus pada Ujian Nasional dan Ujian Sekolah.

Website e-learning MTsN 1 Mataram memiliki beberpa fitur-fitur yang dapat dimanfaatkan oleh guru selama proses pembelajaran. Salah satunya fitur video conference, Akan tetapi, guru belum memanfaatkan fitur video conference yang ada pada website e-learning MTsN 1 Mataram. Dengan memanfaatkan fitur video conference pada website e-learning MTsN 1 Mataram dan dalam proses pembelajaran menggunakan video pembelajaran. Diharapkan pembelajaran matematika berbasis e-learning lebih efektif dan dapat meningkatkan hasil belajar siswa pada materi sistem persamaan linear dua variabel. Sehingga, peneliti tertarik untuk mengadakan penelitian yang berjudul "Efektivitas pembelajaran matematika berbasis e-learning pada materi sistem persamaan linear dua variabel kelas VIII di MTs Negeri 1 Mataram.”

Berdasarkan permasalahan tersebut maka tujuan dalam penelitian ini adalah untuk mengetahui efektivitas pembelajaran matematika berbasis e-learning pada materi sistem persamaan linear dua variabel kelas VIII di MTsN 1 Mataram. 


\section{METODE PELAKSANAAN}

Sesuai dengan tujuan yang ingin dicapai, maka jenis penelitian adalah penelitian deskriptif dengan pendekatan kuantitatif. Penelitian yang dilakukan oleh peneliti adalah bentuk post-test only control design. Pemberian post-test dilakukan setelah diterapkan pembelajaran matematika berbasis e-learning dengan media video pembelajaran, untuk memperoleh data hasil belajar matematika siswa pada materi sistem persamaan linear dua variabel.

Menurut Gunawan (2015), populasi adalah keseluruhan objek penelitian. Sehingga dalam penelitian ini, populasi adalah seluruh siswa kelas VIII di MTsN 1 Mataram pada tahun pelajaran 2020/2021. Untuk menentukan sampel penelitian digunakan teknik cluster random sampling karena populasi homogen. Sampel yang terambil dua kelas yaitu sebanyak 64 siswa. Sampel mendapatkan perlakuan yang sama yaitu menggunakan pembelajaran matematika berbasis e-learning dengan website e-learning MTsN 1 Mataram dan media audio visual murni berupa video pembelajaran dan file materi dan LKPD sistem persamaan linear dua variabel.

Instrumen yang digunakan yaitu tes berupa test akhir (post-test) dalam bentuk uraian sebanyak 4 soal dan diberikan kepada kelas sampel. Sebelum diberikan instrumen posttest, terlebih dahulu dilakukan validitas instrumen oleh 2 validator ahli yaitu dosen dan guru mata pelajaran matematika, dengan membandingkan antara kesesuaian butir soal dengan indikator yang yang diukur, kesesuaian antara standar kompetensi dengan kompetensi dasar dan materi yang diteskan mewakili keseluruhan materi yang diteliti. Secara teknik, pengujian validitas isi dapat dibantu dengan kisi-kisi instrumen dan berdasarkan pendapat ahli. Dari soal-soal tes yang diberikan, semua soal berkaitan dengan materi sistem persamaan linear dua variabel yang telah disampaikan ketika pembelajaran.

Teknik analisis data yang digunakan yaitu analisis statistik deskriptif dan analisis statistik inferensial. Statistik deskriptif adalah statistik yang digunakan untuk mendeskripsikan atau memberi gambaran terhadap objek yang diteliti melalui data sampel atau populasi sebagaimana adanya, tanpa melakukan analisis dan membuat kesimpulan yang berlaku secara umum (Sugiyono, 2007). Analisis statistik deskriptif digunakan untuk mendeskripsikan atau memberi gambaran umum terhadap pemahaman materi matematika siswa dilihat dari hasil belajar siswa pada pembelajaran matematika berbasis e-learning.

Statistik inferensial adalah teknik statistik yaang digunakan untuk menganalisis data sampel dan hasilnya diberlakukan untuk populasi (Sugiyono, 2015). Pada statistik inferensial terdapat statistik parametrik dan non parametrik. Penggunaan statistik parametrik memerlukan terpenuhinya banyak asumsi sehingga penggunaan statistik parametrik harus memenuhi asumsi-asumsi terlebih dahulu. Asumsi utama dari statistik parametrik adalah data berdistribusi normal. Jika asumsi uji normalitas tidak terpenuhi maka digunakanlah statistik non-parametrik. 
Uji normalitas dilakukan untuk mengetahui apakah sampel data berasal dari populasi yang berdistribusi normal (Gunawan, 2013). Dalam penelitian ini, untuk uji normalitas data peneliti menggunakan uji Liliefors. Uji Liliefors dilakukan apabila data masih disajikan secara individu. Uji Liliefors dilakukan dengan mencari nilai $L_{h i t u n g}$ yakni nilai $|\mathrm{F}(\mathrm{zi})-\mathrm{S}(\mathrm{zi})|$ yang terbesar. Dengan kriteria pengujian yaitu jika $L_{\text {hitung }}<L_{\text {tabel }}$, maka $\mathrm{H}_{0}$ diterima sehingga dapat disimpulkan bahwa sampel berasal dari populasi yang berdistribusi normal (Gunawan, 2013).

Apabila uji normalitas terpenuhi, maka uji statistik yang digunakan adalah uji-t dengan jenis pengujian yang diambil adalah Paired sample. Uji-t adalah teknik analisis statistik yang dapat dipergunakan untuk mengetahui apakah terdapat perbedaan yang signifikan dua mean sampel atau tidak (Ananda \& Fadhli, 2018). Dengan kriteria pengujian $\mathrm{H}_{0}$

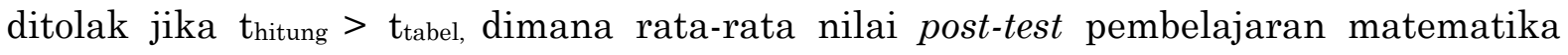
berbasis e-learning dengan media video pembelajaran pada materi SPLDV lebih besar dari rata-rata nilai post-test pembelajaran matematika berbasis e-learning pada materi PGL (Sudjana, 2005).

\section{HASIL DAN PEMBAHASAN}

Setelah diterapkan pembelajaran matematika berbasis e-learning dengan media video pembelajaran pada materi sistem persamaan linear dua variabel serta telah diberikan soal post-test berupa soal uraian sebanyak 4 soal yang telah divalidasi dan dinyatakan valid oleh validator ahli. untuk mengetahui efektif atau tidak pembelajaran berbasis elearning pada materi sistem persamaan linear dua variabel kelas VIII di MTsN 1 Mataram tahun ajaran 2020/2021. Peneliti menganalisis data dari hasil post-test pada materi sistem persamaan linear dua variabel dan pada materi persamaan garis lurus. Data hasil post-test siswa pada kelas sampel dianalisis menggunakan statistik deskriptif.

Tabel 1. Hasil Analisis Data Statistik Deskriptif

\begin{tabular}{ccc}
\hline Statistik & Post-test (SPLDV) & Post-test (PGL) \\
\hline Rata-rata & 79,0450 & 65,3533 \\
Nilai Minimum & 16,0 & 33,2 \\
Nilai Maximum & 100,0 & 98,0 \\
Jumlah & 4.743 & 3.921 \\
Jumlah responden & 60 & 60 \\
\hline
\end{tabular}

Berdasarkan tabel hasil analisis data statistik deskriptif. Pada materi sistem persamaan linear dua variabel, diperoleh rata-rata sebesar 79,0450; nilai maksimum 100,0; nilai minimum 16,0; sedangkan pada materi persamaan garis lurus, diperoleh rata-rata sebesar 65,3533; nilai maksimum 98,0; nilai minimum 33,2; Sehingga diperoleh kategori penskoran untuk materi sistem persamaan linear dua variabel sebagai berikut: 
Tabel 2. Kategori Penskoran SPLDV dan PGL

\begin{tabular}{cccc}
\hline Interval Skor & $f$ SPLDV & $f$ PGL & Kategori \\
\hline $\mathrm{X} \geq 93,4$ & 6 & 2 & Sangat Tinggi \\
$86,7 \leq \mathrm{X}<93,4$ & 16 & 5 & Tinggi \\
$80 \leq \mathrm{X}<86,7$ & 26 & 13 & Sedang \\
$\mathrm{X}<80$ & 12 & 40 & Rendah \\
\hline
\end{tabular}

Berdasarkan tabel kriteria penskoran, kecenderungan tentang tinggi atau rendahnya nilai skor hasil belajar matematika pada materi sistem persamaan linear dua variabel dan persamaan garis lurus, dapat dilihat dari frekuensi tertinggi pada tabel kategori penskoran. Dari perhitungan diperoleh frekuensi tertinggi SPLDV sebanyak 26. Jika dimasukkan dalam interval skor, maka frekuensi SPLDV termasuk dalam kategori sedang. Sedangkan dari perhitungan diperoleh frekuensi tertinggi PGL sebanyak 40. Jika dimasukkan dalam interval skor, maka frekuensi PGL termasuk dalam kategori rendah.

Tabel 4.4 Ketuntasan Klasikal Hasil Belajar Matematika Siswa

\begin{tabular}{cccccc}
\hline Materi & $\begin{array}{c}\text { Jumlah } \\
\text { Siswa }\end{array}$ & KKM & $\begin{array}{c}\text { Jumlah } \\
\text { Tuntas }\end{array}$ & $\begin{array}{c}\text { Jumlah } \\
\text { Tidak } \\
\text { Tuntas }\end{array}$ & $\begin{array}{c}\text { Ketuntasan } \\
\text { Klasikal } \\
(\%)\end{array}$ \\
\hline SPLDV & 60 & \multirow{2}{*}{80} & 48 & 12 & 80 \\
PGL & 60 & & 20 & 40 & 33,3333 \\
\hline
\end{tabular}

Berdasarkan tabel ketuntasan klasikal dapat diketahui bahwa jumlah siswa yang tuntas pada hasil post-test kelas sampel dengan materi sistem persamaan linear dua variabel yaitu 48 siswa, sehingga ketuntasan klasikalnya yaitu 80\%. Sedangkan jumlah siswa yang tuntas pada hasil post-test kelas sampel dengan materi persamaan garis lurus yaitu 20 siswa, sehingga ketuntasan klasikalnya yaitu $33,3333 \%$.

Sesuai dengan pendapat Pujiastutik (2019), pembelajaran e-learning dinyatakan efektif jika nilai ketuntasan hasil belajar mencapai $\geq 75 \%$. Sehingga pembelajaran matematika berbasis e-learning dengan video pembelajaran pada materi sistem persamaan linear dua variabel dikategorikan efektif dengan ketuntasan klasikal 80\%. Sedangkan pembelajaran matematika berbasis e-learning pada materi persamaan garis lurus dikategorikan tidak efektif dengan ketuntasan klasikal 33,3333\%.

Setelah dilakukan analisis statistik deskriptif, Selanjutnya peneliti menguji hasil posttest pada materi sistem persamaan linear dua variabel dan materi persamaan garis lurus dengan analisis statistik inferensial untuk mengetahui lebih lanjut efektif atau tidak pembelajaran matematika berbasis e-learning dengan media video pembelajaran pada materi sistem persamaan linear dua variabel.

Uji normalitas data digunakan untuk memperlihatkan bahwa data sampel berasal dari populasi yang berdistribusi normal. Uji normalitas yang digunakan yaitu uji normalitas Liliefors dengan taraf signifikansi $5 \%$. 
Tabel 4.5 Uji Normalitas Data Post-test PGL dan SPLDV

\begin{tabular}{llll}
\hline Materi & $L_{\text {hitung }}$ & $L_{\text {tabel }}$ & Keterangan \\
\hline SPLDV & 0,1140 & \multirow{2}{*}{0,1144} & Berdistribusi Normal \\
PGL & 0,1097 & & Berdistribusi Normal \\
\hline
\end{tabular}

Berdasarkan tabel uji normalitas data post-test PGL dan SPLDV, dilihat bahwa $L_{\text {hitung }}<$ $L_{\text {tabel }}$, maka $\mathrm{H}_{0}$ diterima sehingga dapat disimpulkan bahwa sampel berasal dari populasi yang berdistribusi normal. Karena uji prasyarat normalitas terpenuhi, maka digunakan statistik parametrik. Dalam penelitian ini statistik parametrik yang digunakan yaitu ujit jenis Paired sample.

Pengujian hipotesis menggunakan uji-t, digunakan untuk mengetahui pembelajaran matematika berbasis e-learning dengan media video pembelajaran efektif atau tidak diterapkan pada materi sistem persamaan linear dua variabel.

Tabel 4.6 Uji-t Paired Sample Data Hasil Post-test

\begin{tabular}{ccccc}
\hline Materi & $\begin{array}{c}\text { Jumlah } \\
\text { siswa }\end{array}$ & $\bar{X}$ & $t_{\text {hitung }}$ & $t_{\text {tabel }}$ \\
\hline SPLDV & 60 & 79,0450 & 5,8811 & 1,67 \\
PGL & 65,3533 & 5811 & \\
\hline
\end{tabular}

Berdasarkan tabel uji-t Paired sample diperoleh nilai thitung $>t_{\text {tabel }}$ pada taraf signifikansi $5 \%$, maka $\mathrm{H}_{0}$ ditolak, dimana Rata-rata nilai post-test pembelajaran matematika berbasis e-learning dengan media video pembelajaran pada materi SPLDV lebih besar dari ratarata nilai post-test pembelajaran matematika berbasis e-learning pada materi PGL, sehingga pembelajaran matematika berbasis e-learning dengan media video pembelajaran efektif diterapkan pada materi sistem persamaan linear dua variabel

Keuntungan menerapkan pembelajaran matematika berbasis e-learning yaitu pada tahap memberikan bahan ajar dapat dilakukan dengan terstruktur dan terjadwal melalui internet, sehingga guru dan siswa dapat menilai sampai berapa jauh bahan ajar dipelajari, siswa juga dapat mempelajari bahan ajar setiap saat dan dimana saja kalau diperlukan karena bahan ajar tersimpan di smartphonenya, bila siswa memerlukan tambahan informasi yang berkaitan dengan bahan yang dipelajarinya, ia dapat melakukan akses internet secara lebih mudah.

Pembelajaran matematika berbasis e-learning relatif lebih efisien karena tidak dibatasi oleh jarak, tempat dan waktu. Selain itu, dapat diikuti dengan jumlah peserta yang banyak, sehingga menambah ilmu pengetahuan dan wawasan yang lebih luas. Sesuai dengan pendapat Nadziroh (2017) bahwa e-learning efektif dalam meningkatkan mutu pembelajaran, karena proses pembelajarannya tidak hanya terpaku dalam satu waktu dan dalam ruangan saja. Adanya kegiatan pembelajaran matematika berbasis e-learning ternyata dapat membantu siswa dalam memahami materi yang dipelajari. Sesuai dengan pendapat Utami \& Cahyono (2020) bahwa e-learning dapat membantu dalam menguasai materi sehingga dapat meningkatkan hasil belajar matematika. 
Pada saat penelitian, peneliti memanfaatkan salah satu fitur yang ada pada website elearning yaitu fitur video coference. Fitur video conference selain dapat digunakan dengan memanfaatkan laptop juga dapat digunakan dengan mengunakan smartphone yaitu dengan cara mendownload aplikasi jits meet. Dengan memanfaatkan fitur video conference guru dan siswa dapat berintraksi secara langsung, siswa juga dapat dibimbing secara langsung dalam menyelesaikan materi dan soal-soal yang belum dipahami oleh siswa, walaupun dari jarak jauh. Sehingga, siswa lebih menguasai dan memahami materi yang diajarkan. Sesuai dengan pendapat Muhardi \& Ponidi (2020) bahwa dengan video conference guru dan peserta didik dapat berintraksi secara langsung dan guru juga dapat dengan mudah menjelaskan materi. Selain itu, Ismawati \& Prasetyo (2021) berpendapat bahwa pembelajaran dengan video conference dapat mendukung pembelajaran jarak jauh, memudahkan siswa untuk menyerap materi pembelajaran yang disampaikan guru karena lebih interaktif sebagai media pembelajaran.

Menurut Sandiwarno (2016), bahwa pembelajaran melalui video conference selain dapat mengoptimalkan adanya intraksi secara langsung antara siswa dan guru, juga dapat menampilkan materi pembelajaran ditampilan dan dapat dilihat oleh semua siswa sehingga, siswa-siswa tidak hanya mendengar penjelasan melainkan dapat juga mencermati materi yang diberikan. Hasil penelitian Ekawardhana (2020) semakin menegaskan bahwa penggunaan video conference dalam proses pembelajaran dikatakan sangat efektif.

Selain itu, peneliti juga menggunakan media pembelajaran berupa video pembelajaran. Video pembelajaran dibuat menggunakan aplikasi screen recorder. Menurut Ziden \& Rahman (2013) Video pembelajaran mampu menggabungkan dan mengintegrasikan berbagai metode dan teknik pembelajaran yang efektif membantu siswa dalam proses pembelajaran dan dapat meningkatkan hasil belajar siswa. Sedangkan menurut Albaniah (2014) bahwa terdapat hubungan yang positif antara penggunaan media video pembelajaran dengan hasil belajar matematika siswa. Hasil penelitian Junita, Rahim \& Salam (2021) menegaskan bahwa pembelajaran e-learning berbantuan video pembelajaran efektif dalam meningkatkan hasil belajar siswa.

Faktor lain yang yang ditemukan saat praktik di lapangan yaitu jam pembelajaran kedua kelas sampel yang dimana tidak ada jam pembelajaran pada mata pelajaran yang lain lagi, sehingga siswa mempunyai waktu yang banyak untuk berdiskusi dan bertanya terkait yang belum dipahami saat pembelajaran berlangsung. Dari hasil wawancara dengan siswa secara lisan melalui video conference, setelah jam pembelajaran matematika tidak ada jam pembelajaran yang lain. Sehingga, sebagian siswa meminta berdiskusi dengan guru di luar jam pembelajaran matematika agar lebih paham dengan materi yang diajarkan. Menurut pendapat Lestari (2015) terdapat pengaruh yang signifikan antara waktu belajar terhadap hasil belajar matematika. Pendapat Sari (2019) semakin menegaskan bahwa terdapat pengaruh yang signifikan antara waktu belajar terhadap hasil belajar matematika siswa, dengan waktu belajar yang panjang akan dapat meningkatkan hasil belajar matematika siswa. 


\section{SIMPULAN}

Berdasarkan hasil penelitian dan pembahasan maka dapat disimpulkan bahwa "Pembelajaran matematika berbasis e-learning dengan media video pembelajaran efektif diterapkan pada materi sistem persamaan linear dua variabel kelas VIII di MTsN 1 Mataram tahun ajaran 2020/2021.

\section{REFERENSI}

Albaniah, T. A. N. T. Y. 2014. Hubungan Penggunaan Media Video Pembelajaran Dengan Hasil Belajar Siswa Pada Mata Pelajaran Matematika Kelas IV SDN 76/1 Sungai Buluh. 17. Diunduh dari http://ecampus. fkip. unja. ac. id/eskripsi/data/pdf/jurnal_mhs/artikel/A1D109136. pdf.

Ananda, R. \& Fadhli, M. 2018. Statistik Pendidikan Teori dan Praktik dalam Pendidikan. Medan: CV. Widya Puspita.

Ekawardhana, N. E. 2020. Efektivitas Pembelajaran Dengan Menggunakan Media Video Conference. Seminar Nasional Ilmu Terapan (SNITER) (Vol. 4, No. 1).

Fathurrohman, M. \& Sulistyorini. 2012. Belajar Dan Pembelajaran Meningkatkan Mutu Pembelajaran Sesuai Standar Nasional. Yogyakarta: Teras.

Gunawan, M. A. 2013. Statistika Untuk Penelitian Pendidikan. Yogyakarta: Parama Publishing.

Gunawan, M. A. 2015. Statistik Penelitian Bidang Pendidikan, Psikologi dan Sosial. Yogyakarta: Parama Publishing.

Hamdani. 2011. Strategi Belajar Mengajar. Bandung: Pustaka Setia.

Ismawati, D., \& Prasetyo, I. 2020. Efektivitas pembelajaran menggunakan video zoom cloud meeting pada anak usia dini era pandemi covid-19. Jurnal Obsesi: Jurnal Pendidikan Anak Usia Dini, 5(1), 665-675.

Junita, T., Rahim, U., \& Salam, M. 2021. Efektivitas Model Pembelajaran Online Berbantuan Video Pembelajaran Terhadap Hasil Belajar Matematika Siswa Kelas VII SMP Negeri 3 Kendari. Jurnal Penelitian Pendidikan Matematika, 9(1), 99-112.

Lestari, I. (2015). Pengaruh waktu belajar dan minat belajar terhadap hasil belajar matematika. Formatif: jurnal ilmiah pendidikan MIPA, 3(2).

Muhardi, M., \& Ponidi, P. 2020. Pembelajaran Online yang Efektif di Masa Pandemik Covid-19 Studi Kasus di SMP Negeri 4 Pakem Sleman. INTEK: Jurnal Informatika Dan Teknologi Informasi, 3(1), 41-51.

Nadziroh, F. 2017. The Analisa Efektifitas Sistem Pembelajaran Berbasis E-Learning. Journal of Computer Science and Visual Communication Design, 2(1), 1-14.

Nu'man, A. Z. 2014. Efektivitas Penerapan E-Learning Model Edmodo Dalam Pembelajaran Pendidikan Agama Islam Terhadap Hasil Belajar Siswa (Studi Kasus: SMK Muhammadiyah 1 Sukoharjo). Jurnal DutaCom. 7(1):1-13.

Pujiastutik, H. 2019. Efektivitas Penggunaan Media Pembelajaran E-Learning Berbasis Web Pada Mata Kuliah Belajar Pembelajaran I Terhadap Hasil Belajar Mahasiswa. Jurnal Teladan: Jurnal Ilmu Pendidikan dan Pembelajaran, 4(1), 25-36.

Ristianti, L. 2017. Penerapan Media Video Dalam Meningkatkan Minat Belajar Siswa Pada Mata Pelajaran SKI di Kelas VII MTs Paradigma Palembang. Skripsi. UIN Raden Fatah.

Sandiwarno, S. (2016). Perancangan Model E-Learning Berbasis Collaborative Video Conference Learning Guna Mendapatkan Hasil Pembelajaran yang Efektif dan Efisien. Jurnal Ilmiah FIFO, 8(2), 191-200.

Sari, B. T. W. 2019. Pengaruh Durasi Belajar Terhadap Hasil Belajar Matematika Siswa Kelas 5 Ledok 006 Salatiga. Jurnal Review Pendidikan dan Pengajaran, 2(1), 139-144.

Sudjana, 2005. Metode Statistika. Bandung: Tarsito.

Sugiyono. 2007. Statistika Untuk Penelitian. Bandung: Alfabeta.

Sugiyono. 2015. Metode Penelitian Pendidikan Pendekatan Kuantitatif, Kualitatif, dan R\&D. Bandung. Alfabeta.

Sutarto \& Wuryanto. 2018. Geometri, Teknologi, dan Bagaimana Penggunaannya dalam Kaitannya dengan Keterampilan Pembuktian. Prisma 1: 904-908. 
Utami,Y. P., \& Cahyono, D. A. D. 2020. Study at Home: Analisis Kesulitan Belajar Matematika Pada Proses Pembelajaran Daring. Jurnal Ilmiah Matematika Realistik, 1(1), 20-26.

Ziden, A. A., \& Rahman, M. F. A. (2013). The Effectiveness of Web-Based Multimedia Applications Simulation in Teaching and Learning. International Journal of Instruction, 6(2), 211-222.

Zulkardi. 2002. Developing a Learning Envorinment on Realistic Mathematics Education for Indonesian Students Teachers. Thesis. University of Twente. Enschede: Printpartners Ipskamp. 